\title{
COMPARAÇÃO ENTRE AS CONDIÇÕES DE ACESSIBILIDADE E INCLUSÃO SOCIAL DE 25 INSTITUIÇÕES PÚBLICAS DE ENSINO SUPERIOR DO BRASIL E UM ESTUDO DE CASO NA UFTM
}

\author{
A COMPARISON BETWEEN THE CONDITIONS OF \\ ACCESSIBILITY AND SOCIAL INCLUSION OF 25 \\ PUBLIC INSTITUTIONS OF HIGHER EDUCATION \\ IN BRAZIL AND A CASE STUDY AT UFTM
}

\author{
Paloma Bessa Ferreira* \\ Luiz Fernando Resende dos Santos Anjo* \\ Geoffroy Roger Pointer Malpass \\ Ana Claudia Granato Malpass
}

\begin{abstract}
RESUMO: O presente estudo buscou dados que retratem a realidade das Instituições Públicas de Ensino Superior do país, no tocante à acessibilidade e inclusão social. Para isso o estudo teve como parâmetro 25 instituições de ensino superior públicas do país, as quais foram questionadas via Sistema de Informação ao Cidadão a respeito dos dados quantitativos de pessoas com deficiência na instituição (servidores, docentes e discentes) e outros dados de acessibilidade e inclusão social da instituição. Além disso, foi feito um estudo de caso na Universidade Federal do Triângulo Mineiro para maior detalhamento das mesmas condições nesta instituição. O trabalho foi realizado considerando a legislação brasileira de amparo às pessoas com deficiência e pertinentes à acessibilidade e inclusão social, bem como foi utilizada pesquisa documental e bibliográfica para aprofundamento na temática. Verificou-se que as IES estão investindo na implementação da acessibilidade, com aquisição de Tecnologias Assistivas e adaptações de suas edificações. No entanto, a falta de recursos, questões atitudinais, conscientização da comunidade acadêmica, implantação de políticas de acessibilidade e serviço de atendimento especializado ainda são obstáculos pontuados por algumas instituições. Verificou-se que todas as instituições analisadas ofertam a disciplina Libras para os discentes e servidores. Conclui-se assim que a
\end{abstract}

Mestre em Inovação Tecnológica pela Universidade Federal do Triângulo Mineiro (UFTM). Contato: palomabessapb@gmail.com

* Doutor em Engenharia Civil pela Universidade Estadual de Campinas (UNICAMP). Docente do Programa de Mestrado Profissional em Inovação Tecnológica e reitor da Universidade Federal do Triângulo Mineiro (UFTM). Contato: luiz.anjo@uftm.edu.br

*** Doutor em Ciências pela Universidade de São Paulo (USP). Docente do Programa de Mestrado Profissional em Inovação Tecnológica da Universidade Federal do Triângulo Mineiro (UFTM). Contato: geoffroy.malpass@uftm.edu.br

*** Doutora em Ciências pela Universidade de São Paulo (USP). Docente do Programa de Mestrado Profissional em Inovação Tecnológica da Universidade Federal do Triângulo Mineiro (UFTM). Contato: ana.malpass@uftm.edu.br 
busca pela implementação da acessibilidade e inclusão social ainda é uma realidade a ser enfrentada pelas instituições superiores públicas no país.

Palavras-chave: Deficiência; Acessibilidade; Inclusão social; Instituições públicas de ensino superior.

ABSTRACT: The present study sought data that portrays the reality of Public Institutions of Higher Education in the country, with regard to accessibility and social inclusion. For this purpose, the study had as parameter 25 public higher education institutions (HEIs) in the country, which were questioned via the Citizen Information System (e-SIC) regarding the quantitative data of people with disabilities in the institution (civil servants, teachers and students) and other accessibility and social inclusion data of the institution. In addition, a case study was made at the Universidade Federal do Triângulo Mineiro to further detail the same conditions at this institution. The work was carried out considering the Brazilian legislation of support for people with disabilities and pertinent to accessibility and social inclusion, as well as documentary and bibliographic research was used to deepen the theme. It was found that the HEls are investing in the implementation of accessibility, with the acquisition of Assistive Technologies and adaptations of their buildings. However, the lack of resources, attitudinal issues, awareness of the academic community, implementation of accessibility policies and specialized service are still obstacles pointed out by some institutions. It was found that all the institutions analyzed offer the Libras discipline to students and civil servants. It is concluded that the search for the implementation of accessibility and social inclusion is still a reality to be faced by the higher public institutions in the country.

Keywords: Disability; Accessibility; Social inclusion; Public higher education institutions.

\section{INTRODUÇÃO}

O Brasil possui mais de 45 milhões de brasileiros cadastrados com algum tipo de deficiência, considerando os dados do censo do último IBGE em 2010 (IBGE, 2010). Dessa forma, há um número expressivo de pessoas com deficiência que precisam ter seus direitos efetivamente garantidos para participarem ativamente da sociedade com igualdade de condições dos demais cidadãos.

Conforme Kamio e Sassi (2010), o termo inclusão social consiste na:

adequação da sociedade e de infraestruturas para que se possa incluir pessoas com características especiais em sistemas sociais, eliminando, assim, todas as barreiras físicas, problemáticas e atitudinais para que estes tenham acesso a 
serviços, espaços, informações e bens necessários a seu desenvolvimento pessoal, social, educacional e profissional.

Entretanto, a inclusão social das pessoas com deficiência encontra-se prejudicada devido às barreiras existentes no meio social, como barreiras arquitetônicas, tecnológicas, visuais e atitudinais. Dessa forma, para eliminação dessas barreiras no contexto social há a necessidade de implementar a acessibilidade. Embora haja a proteção das pessoas com deficiência pelo ordenamento jurídico, é imprescindível que o Estado crie condições para a efetivação desses direitos com a implementação da acessibilidade. O termo acessibilidade é definido no inciso I do art. 3ํ da Lei 13146 de 2015 (BRASIL, 2015), como sendo a:

possibilidade e condição de alcance para utilização, com segurança e autonomia, de espaços, mobiliários, equipamentos urbanos, edificações, transportes, informação e comunicação, inclusive seus sistemas e tecnologias, bem como de outros serviços e instalações abertos ao público, de uso público ou privados, de uso coletivo, tanto na zona urbana como na rural, por pessoa com deficiência ou com mobilidade reduzida.

Ressalta-se que a Carta Magna traz como papel do Estado a proteção dos direitos à pessoa com deficiência e a garantia a todos dos direitos fundamentais como direito à saúde, moradia, segurança, educação e livre locomoção em território nacional. Entretanto, o pleno exercício da cidadania muitas vezes encontra-se prejudicado devido às barreiras existentes no meio social, como barreiras arquitetônicas, tecnológicas, visuais e atitudinais.

No tocante à educação, observa-se que de acordo com dados do INEP (2017), há mais de 38 mil alunos com deficiência cursando ensino superior no país. O que demonstra a necessidade de as Instituições de Ensino Superior (IES), estabelecerem diretrizes para implementarem à acessibilidade, para garantir aos discentes as condições não somente para o ingresso, mas para concluírem os cursos de graduação.

O emprego da inovação tecnológica nas instituições de ensino pode ser uma peça fundamental para a eliminação das barreiras existentes e a 
efetivação das normas de acessibilidade na comunidade acadêmica, bem como na sociedade. Assim, é imprescindível a realização de novas pesquisas acerca da acessibilidade no ensino superior brasileiro, para buscar melhorias na qualidade do acesso à educação do país.

Diante disso, o presente estudo teve como objetivo buscar dados que retratem a realidade em relação à acessibilidade e inclusão social em algumas IES públicas do país para averiguar se o ensino superior público nacional está, realmente, em consonância com as normas de acessibilidade e inclusão social previstas no ordenamento jurídico brasileiro e realizar um estudo de caso na Universidade Federal do Triangulo Mineiro.

\section{METODOLOGIA}

O presente trabalho baseou-se em uma pesquisa bibliográfica e documental, com coleta de dados quali e quantitativos, e, posteriormente, uma pesquisa de campo. Silva e Malfitano (2017) reportam que, quando realizada adequadamente, uma pesquisa bibliográfica constitui-se em um importante instrumento para dar visibilidade a temas pouco explorados e para postular hipóteses para problemas de pesquisa.

Realizou-se ainda uma pesquisa documental qualitativa no ordenamento jurídico brasileiro para verificar quais são os direitos de uma pessoa com deficiência, bem como a legislação pertinente à acessibilidade e inclusão social da pessoa com deficiência. Além disso, para retratar a realidade em acessibilidade nas IES do país, foram questionadas 25 Instituições Federais de Ensino Superior (IFES) de todas as regiões do país, através do sistema Sistema Eletrônico de Informações ao Cidadão (e-SIC, que propicia que qualquer pessoa, física ou jurídica, solicite pedidos de acesso à informação, acompanhe o prazo e receba a resposta da solicitação realizada para órgãos e entidades do Executivo) das instituições para obter informações a respeito dos quesitos de acessibilidade e inclusão que as mesmas já apresentam ou ainda precisam ser implementadas. 
Além das IFES também foram consultadas três instituições públicas de ensino superior estaduais, a Universidade de São Paulo - USP, a Universidade de Campinas - Unicamp e a Universidade Estadual Paulista - Unesp, todas localizadas no estado de São Paulo. A USP e a Unicamp foram escolhidas por ocuparem a segunda e a terceira colocação no ranking de melhores universidades da América Latina em 2020, respectivamente, de acordo com o Times Higher Education (THE, 2020). Considerando essa classificação, essas universidades foram consultadas para verificar se são referências na implementação da acessibilidade em seus campi. Já a Unesp foi classificada entre as dez melhores universidades da América Latina, e a escolha dessa instituição para consulta se deu devido à constatação do elevado número de publicações de artigos científicos de docentes dessa universidade na área de Acessibilidade.

Os questionamentos realizados no período de 2019 a 2020 foram:

- Qual o quantitativo de docentes, discentes e servidores com deficiência especiais na instituição?

- Quais Tecnologias Assistivas (TA) são utilizadas pela instituição por docentes, discentes e servidores para melhor desempenho de suas atividades?

- Quais adaptações existentes nas edificações da instituição para atender docentes, discentes e servidores com deficiência?

- Quais adaptações na instituição ainda serão feitas para atender docentes, discentes e servidores com deficiência?

- Existem cursos de Libras e outros de capacitação na instituição para implementar acessibilidade e inclusão social na instituição?

Foi realizado ainda um estudo de caso na Universidade Federal do Triângulo Mineiro (UFTM) para maior detalhamento de como a instituição está dentro do cenário nacional. 


\section{RESULTADOS E DISCUSSÃO}

Comparação da acessibilidade e inclusão social em 25 IES do Brasil

Responderam ao questionamento via e-SIC 25 IFES: UFTM, IFTM, UFMG, UFU, UFV, UFSCAR, Unifesp, UFES, UFRJ, UFRGS, UFTPR, UnB, UFG, UFMS, UFMT, UFBA, UFC, UFMA, UFRN, UFPE, UFAM, UFT, além das instituições estaduais USP, Unicamp e Unesp ${ }^{1}$. Os dados foram reunidos e são apresentados no Quadro 1.

1 Universidade Federal do Triângulo Mineiro (UFTM); Instituto Federal do Triângulo Mineiro (IFTM); Universidade Federal de Minas Gerais (UFMG); Universidade Federal de Uberlândia (UFU); Universidade Federal de Viçosa (UFV); Universidade Federal de São Carlos (UFSCAR); Universidade Federal de São Paulo (Unifesp); Universidade Federal do Espirito Santo (UFES); Universidade Federal do Rio de Janeiro (UFRJ); Universidade Federal do Rio Grande do Sul (UFRGS);Universidade Federal Tecnológica do Paraná (UFTPR); Universidade de Brasília (UnB); Universidade Federal de Goiás (UFG); Universidade Federal de Mato Grosso do Sul (UFMS); Universidade Federal de mato Grosso (UFMT); Universidade Federal da Bahia (UFBA); Universidade Federal do Ceará (UFC); Universidade Federal do Maranhão (UFMA); Universidade Federal do Rio Grande do Norte (UFRN); Universidade Federal de Pernambuco (UFPE); Universidade Federal do Amazonas (AFAM); Universidade Federal do Tocantins (UFT); Universidade de São Paulo (USP); Universidade de Campinas (Unicamp); Universidade Estadual Paulista (Unesp). 
Quadro 1: Dados institucionais informados via e-SIC pelas IES avaliadas.

\begin{tabular}{|c|c|c|c|c|c|}
\hline IES & $\begin{array}{l}\text { Servidores com } \\
\text { deficiência }\end{array}$ & $\begin{array}{l}\text { Discentes com } \\
\text { deficiência }\end{array}$ & TA que possuem & $\begin{array}{l}\text { Adaptações arquitetônicas para } \\
\text { promover acessibilidade }\end{array}$ & $\begin{array}{l}\text { Cursos de libras, } \\
\text { capacitação em } \\
\text { acessibilidade }\end{array}$ \\
\hline USP & Não informado & $\begin{array}{l}206 \text { discentes } \\
\text { (todos os } \\
\text { campi) }\end{array}$ & $\begin{array}{l}\text { Focus } 40 \text { - Tecasitiva (Linha Braile); } \\
\text { Teclado ampliado para pessoa com } \\
\text { deficiência visual; Leitor Autômato - } \\
\text { SARA, Ampliador digital - SARA. }\end{array}$ & $\begin{array}{c}\text { As adaptações arquitetônicas promovidas } \\
\text { pelo USP Legal contam com Braile, rampas } \\
\text { de acesso, corrimãos duplos, calçadas } \\
\text { reguladas e elevadores nas unidades de } \\
\text { ensino. }\end{array}$ & $\begin{array}{l}\text { Curso de Libras para alunos } \\
\text { oferecidos como ensino à } \\
\text { distância. Cursos de } \\
\text { capacitação para servidores } \\
\text { estão em análise. }\end{array}$ \\
\hline UNICAMP & 100 servidores & 48 discentes & $\begin{array}{c}\text { Ampliador acoplado a TV, caneta } \\
\text { scanner, computadores adaptados, } \\
\text { leitor instantâneo de temperatura em } \\
\text { áudio, transportador portátil de } \\
\text { pessoas com deficiência, impressora } \\
\text { 3D, dois tipos de impressora Braille, } \\
\text { lente de aumento esférica, linha } \\
\text { Braille, lupa eletrônica portátil, } \\
\text { máquinas de escrever Braille, } \\
\text { notebooks com tecnologia assistiva, } \\
\text { rotuladora Braile, scanner para leitura } \\
\text { em áudio automática, scanner portátil, } \\
\text { scanner de texto impresso e com } \\
\text { reprodução em áudio, scanners para } \\
\text { materiais acessíveis, teclado com } \\
\text { teclas em Braile e caracteres } \\
\text { ampliados de alto contraste, } \\
\text { conversor com rapidez vários tipos de } \\
\text { textos e imagens, editor e gravador de } \\
\text { áudio e vídeo, conversor de texto em } \\
\text { áudio, software para impressão em } \\
\text { Braile, leitor de tela por sintetizador de } \\
\text { voz, sistema operacional para uso por } \\
\text { pessoas com deficiência visual, } \\
\text { conversor automático de partituras }\end{array}$ & $\begin{array}{c}\text { Elevadores, sanitários acessíveis, rampas. } \\
\text { Foi criado um Núcleo de Acessibilidade } \\
\text { para os prédios modulados, que } \\
\text { contemplam dois sanitários para pessoas } \\
\text { com deficiência e elevador inclusivo. Está } \\
\text { em andamento o Projeto "Por uma Unicamp } \\
\text { Acessível”, o qual se propõe a conhecer a } \\
\text { real situação de acessibilidade de cada } \\
\text { edificação. Ainda em } 2020 \text { entregará o } \\
\text { relatório da situação de } 17 \text { dos edifícios } \\
\text { mais utilizados pelos estudantes, docentes } \\
\text { e funcionários, quando as adaptações } \\
\text { necessárias para cada edificação serão } \\
\text { elencadas. }\end{array}$ & $\begin{array}{l}\text { Incluiu o curso de Libras em } \\
\text { seu portfólio em } 2019 . \\
\text { Nesse ano foram oferecidas } \\
\text { cinco turmas com quinze } \\
\text { vagas cada para } \\
\text { capacitação de servidores e } \\
56 \text { servidores concluíram o } \\
\text { curso. Para o primeiro } \\
\text { semestre de } 2020 \text { está } \\
\text { previsto a oferta do curso de } \\
\text { Libras com duas turmas. }\end{array}$ \\
\hline
\end{tabular}




\begin{tabular}{|c|c|c|c|c|c|}
\hline & & & \begin{tabular}{|c|} 
impressas para o código em Braile, \\
leitores de telas, softwares para \\
notação e edição de partituras \\
musicais, controle de computador, \\
conversor de textos para serem \\
impressos em código Braile, \\
ampliador de telas para Windows, 832 \\
livros em Braille, 475 audiolivros, \\
62 materiais pedagógicos, ampliador \\
de caracteres, computador Braile, \\
máquina fusora de relevos, lupa \\
eletrônica de mão, folheador \\
eletrônico, linha Braile.
\end{tabular} & & \\
\hline UNESP & Não informado & $\begin{array}{l}599 \text { discentes } \\
\text { (todos os } \\
\text { campi) }\end{array}$ & $\begin{array}{c}\text { Softwares de leitores de tela (NVDA), } \\
\text { Scanners com OCR, Impressoras e } \\
\text { linha Braile, Lupas eletrônicas, e } \\
\text { tradutores e intérpretes de LIBRAS } \\
\text { em salas de } \\
\text { aula para graduandos e pós } \\
\text { graduandos }\end{array}$ & $\begin{array}{c}\text { Mapas táteis e piso tátil, rampas, banheiros } \\
\text { adaptados, plataformas mecânicas, } \\
\text { calçadas, acessos, estacionamentos } \\
\text { preferenciais. Dispõe de condutores } \\
\text { bolsistas para alunos de baixa visão ou } \\
\text { cegos }\end{array}$ & $\begin{array}{l}\text { Oferta da disciplina de } \\
\text { Libras para os discentes. A } \\
\text { Unesp também oferece } \\
\text { capacitação em educação } \\
\text { inclusiva }\end{array}$ \\
\hline UFSCAR & 12 professores & 53 discentes & $\begin{array}{c}\text { A Secretaria Geral de Informática de } \\
\text { UFSCar, para seus websites, } \\
\text { implementa as TA definidas pelos } \\
\text { padrões W3C "Web Content } \\
\text { Accessibility Guidelines" (WCAG 2.0) } \\
\text { e "Authoring Tool Accessibility } \\
\text { Guidelines" (ATAG 2.0). }\end{array}$ & $\begin{array}{l}\text { Rampas de acesso, sanitários, com barras } \\
\text { de apoio, altura de vaso sanitário e pia, } \\
\text { porta com puxador; piso tátil de alerta e } \\
\text { direcional; elevadores, corrimãos, guarda- } \\
\text { corpos e guias de balizamento em escadas } \\
\text { e rampas; vagas privativas nos } \\
\text { estacionamentos; Faixas de pedestres } \\
\text { elevadas em pontos estratégicos; Guias } \\
\text { rebaixadas em calçadas A prioridade é } \\
\text { onde há edifícios mais antigos, e } \\
\text { edificações coletivas. }\end{array}$ & $\begin{array}{l}\text { Curso regular de Libras para } \\
\text { comunidade interna e } \\
\text { externa. Curso Corporativo } \\
\text { para atendimento interno, } \\
\text { bem como para atendimento } \\
\text { de empresas da região. }\end{array}$ \\
\hline UFMG & 138 servidores & 480 discentes & $\begin{array}{l}\text { Softwares de leitores de tela (NVDA) } \\
\text { Lupa Manual, lupa digital, diversos } \\
\text { softwares: transcritor áudio-texto, para }\end{array}$ & $\begin{array}{l}\text { Elevador, rampa, banheiro adaptado, } \\
\text { plataforma elevatória e mobiliário adaptado. }\end{array}$ & $\begin{array}{l}\text { Curso de Libras (para } \\
\text { comunidade interna e } \\
\text { externa); Curso de }\end{array}$ \\
\hline
\end{tabular}




\begin{tabular}{|c|c|c|c|c|c|}
\hline & & & $\begin{array}{l}\text { auxílio em Matemática, material } \\
\text { em Braille, alto-relevo em 3D }\end{array}$ & & $\begin{array}{c}\text { Graduação em Letras-Libras } \\
\text { e a disciplina de } \\
\text { Fundamentos de Libras } \\
\text { online. }\end{array}$ \\
\hline UFES & 40 servidores & 259 discentes & Impressora e linha Braile e VPAD. & $\begin{array}{c}\text { As calçadas estão sendo refeitas para } \\
\text { modelo mais acessível. Os prédios novos já } \\
\text { têm rampas. Os antigos somente escadas, } \\
\text { sem plataformas elevatórias. Construção de } \\
\text { sala de recursos na biblioteca central junto } \\
\text { com um laboratório de pesquisa e extensão } \\
\text { em acessibilidade. Compra de } \\
\text { equipamentos, que está ainda na fase } \\
\text { licitatória. }\end{array}$ & $\begin{array}{l}\text { Campanha publicitária de } \\
\text { orientação. Formação de } \\
\text { professores, apoio } \\
\text { pedagógico para alunos. } \\
\text { Curso de Letras-Libras, } \\
\text { Central de Libras com } \\
\text { intérpretes concursados. }\end{array}$ \\
\hline UFTPR & 227 servidores & $\begin{array}{l}\text { Não foi } \\
\text { informado }\end{array}$ & \begin{tabular}{|c} 
Possui monitores de vídeo com \\
dimensões maiores; disciplina \\
relacionada a TA, com produções \\
decorrentes da disciplina: Mesa \\
especial para instalação de \\
computador e adaptação de software \\
para comunicação (ETM). Alunos da \\
Engenharia Mecânica criaram mesa \\
de atividades para criança com \\
paralisia, cadeira postural em auxílio à \\
fisioterapia de crianças com \\
tetraplegia, criação de órteses para \\
crianças com deficiência sensório- \\
motora com a Impressão 3D.
\end{tabular} & $\begin{array}{l}\text { Rampas, elevadores, cadeiras de rodas, } \\
\text { alceadores de escada, corrimão, piso } \\
\text { podotátil, reforma de instalações físicas. } \\
\text { Novos investimentos visando adequar as } \\
\text { instalações para aprimorar o atendimento na } \\
\text { Universidade serão realizados. }\end{array}$ & $\begin{array}{l}\text { Há oferta de Libras para } \\
\text { toda comunidade acadêmica }\end{array}$ \\
\hline UFRN & 94 servidores & 452 discentes & $\begin{array}{c}\text { Notebook, Laboratório de } \\
\text { Acessibilidade na Biblioteca CentraL } \\
\text { para estudantes com deficiência } \\
\text { visual. }\end{array}$ & $\begin{array}{c}\text { Não possui informação sobre adaptações. } \\
\text { Mas diz que UFRN obedece a legislação, } \\
\text { sendo adotadas todas as modificaçôes } \\
\text { previstas em Lei. }\end{array}$ & $\begin{array}{l}\text { Cursos de Libras para } \\
\text { comunidade, externa e } \\
\text { interna. Oferta cursos para } \\
\text { capacitação de servidores. }\end{array}$ \\
\hline
\end{tabular}

Fonte: Ferreira, 2020 
O quadro 3 resume os dados que foram mais relevantes para a discussão deste trabalho, mas os dados completos encontram-se em Ferreira (2020). Principalmente após a vigência do Estatuto da Pessoa com Deficiência, regulamentado pela Lei 13.146/ 2015 (BRASIL, 2015), cresceu a responsabilidade das IES no país em promover a inclusão social e atender ao disposto na legislação brasileira referente à acessibilidade fornecendo, consequentemente, condições adequadas para acesso de todos independentemente de possuírem alguma deficiência ou não. Com relação às IFES, ressalta-se que o Programa Incluir: Acessibilidade na Educação Superior do Ministério da Educação traçou diretrizes, bem como incentivos orçamentários para essas universidades implementarem medidas de acessibilidade, tais como, adaptações em suas edificações de acordo com as Normas Técnicas NBR 9050 (ABNT, 2015), além da aquisição de TA para atender a comunidade acadêmica com deficiência.

Dentre as instituições consultadas, observa-se que com relação ao número de servidores com deficiência, a UFTPR é a universidade com maior quantitativo, possuindo 227 servidores, seguida da UFMG, com 138 servidores. Ressalta-se que as universidades USP, Unesp, UnB, UFG, UFBA e UFT não informaram o quantitativo de funcionários com deficiência, pois segundo as instituições, seus setores de Recursos Humanos não possuem esses dados quantitativos.

Já quanto ao quantitativo de alunos com deficiência das instituições, a Unesp lidera com 599 discentes com deficiência considerando todos os seus campi. Em segundo lugar, tem-se a UFMG com 480 discentes, e em terceiro a UFRN com 452 discentes. Com relação a USP, foi informado que do seu quantitativo de alunos com deficiência, 45 ingressaram no ano de 2020. Salienta-se que de acordo com o Censo da Educação Superior (INEP, 2017), o número de ingressantes com deficiência no ensino superior é maior nos últimos anos, considerando as políticas de cotas.

Levando-se em conta a aquisição de TA, a Unicamp possui grande listagem de equipamentos para atendimento dos diversos tipos de deficiência. Isso reflete a preocupação da instituição no recebimento de pessoas com deficiência, apesar de não possuir um quantitativo tão expressivo de pessoas 
com deficiência na comunidade acadêmica, se comparado com outras instituições. Dessa forma, salienta-se a importância de as instituições estarem preparadas para o recebimento de pessoas com deficiência e proporcionarem a essas condições adequadas de acesso e atendimento no serviço público oferecido.

As universidades UFSCAR, UFRJ e UFTPR destacaram em suas informações a produção científica de TA dentro da própria universidade, seja com a produção de softwares ou materiais adaptados para beneficiar a comunidade acadêmica ou a comunidade externa. A produção científica na temática pode ser uma saída para que as universidades não dependam apenas de recurso orçamentário para implementar acessibilidade. A produção científica nessa área por meio de projetos de pesquisa e extensão pode ainda auxiliar a preparar os discentes em sua formação na prestação de serviços em prol das necessidades da sociedade. A UFES informou que dispõe de produtos de TA, no entanto, não houve treinamento para operacionalizar esses equipamentos. Dessa forma, destaca-se a importância de preparar/treinar os servidores e docentes para a utilização de produtos de TA disponíveis na instituição.

No quesito adaptações das edificações para atender a acessibilidade verifica-se que as instituições, tanto estaduais quanto federais, estão adequando suas edificações de acordo com as normas técnicas de acessibilidade e inclusão social. Destaca-se que os itens rampas, adaptação de bebedouros e sanitários foram os itens mais comuns apontados entre as instituições consultadas. Verifica-se ainda que as instituições estaduais (USP, Unicamp e Unesp) foram as pioneiras nas adequações de suas edificações, enquanto algumas instituições ainda estão implementando essas medidas. Uma possível justificativa seria o fato de as universidades estaduais citadas disporem de um orçamento maior para o desenvolvimento dessas adequações.

Além disso, outro entrave apontado pelas universidades é a necessidade de adaptação de prédios mais antigos e muitas vezes tombado pelo patrimônio histórico. No entanto, mesmo sendo um edifício público tombado que tem que ser preservado, salienta-se a necessidade de garantir os princípios constitucionais da livre locomoção em território nacional e direito à igualdade, 
de forma que o prédio público possa ser acessado por todos, independentemente de possuírem deficiência ou não. O propósito da acessibilidade consiste justamente nesse aspecto na garantia da pessoa com deficiência em exercer plenamente os seus direitos e para isso deve haver a eliminação das barreiras no meio social. De acordo com o $§ 2^{\circ}$ do art. 42 da Lei 13146/2015 (BRASIL, 2015), o poder público deverá implementar "soluções destinadas à eliminação, à redução ou à superação de barreiras para a promoção do acesso a todo patrimônio cultural, observadas as normas de acessibilidade, ambientais e de proteção do patrimônio histórico e artístico nacional." Além disso, conforme art. 30 do Decreto Federal no 5.296/2004 (BRASIL, 2004), que rege a Lei Federal 10098/2000, a adaptação de bens culturais imóveis deve estar em consonância com o disposto na Instrução Normativa nำ1 do Instituto do Patrimônio Histórico e Artístico Nacional (IPHAN). Essa instrução normativa regulamenta a respeito da acessibilidade em bens culturais imóveis. De acordo com o item 1.1 desta instrução normativa "as soluções adotadas para a eliminação, redução ou superação de barreiras na promoção da acessibilidade aos bens culturais imóveis devem compatibilizarse com a sua preservação e, em cada caso específico, assegurar condições de acesso, de trânsito, de orientação e de comunicação, facilitando a utilização desses bens e a compreensão de seus acervos para todo o público"

Além disso, o IPHAN disponibiliza desde 2014 para download gratuito o Caderno Técnico no 09 - Mobilidade e acessibilidade urbana em centros históricos, em seu portal eletrônico (BERNARDES, 2014). Portanto, é importante haver a preservação do valor histórico do bem imóvel e a adaptação necessária para haver acessibilidade e garantia do princípio da igualdade.

Com relação a capacitação dos discentes, observa-se que 100\% das universidades consultadas informaram a oferta da disciplina Libras (nesta disciplina os alunos aprendem a se comunicar em língua de sinais, entendo a condição linguística e cultural dos surdos), para os alunos cursarem em suas matrizes curriculares seja em caráter obrigatório ou como disciplina optativa. No que se refere à capacitação do corpo docente e técnico administrativo para melhor recebimento de uma pessoa com deficiência, destaca-se que 53,84\% 
das universidades consultadas informaram que ofertam cursos de Libras ou de preparação dos servidores com relação à acessibilidade. Dessa forma, observa-se que ainda há a necessidade de muitas universidades investirem em cursos de preparação para o recebimento de uma pessoa com deficiência, sendo que esses cursos podem ser o diferencial para um bom atendimento e uma comunicação efetiva.

No caso das IFES, os recursos financeiros disponibilizados pelo Programa Incluir podem não ter sido suficientes para que essas instituições concluíssem as obras para atender plenamente a acessibilidade e inclusão social. Verificase que as obras ainda estão em andamento, e devido ao fato de dependerem de recursos orçamentários, poderá ocorrer uma demora para a conclusão da implementação da acessibilidade em seus espaços.

No entanto, ainda que tenham um orçamento reduzido, é preciso que as IFES tracem diretrizes e destinem parte de seus recursos internos para a implementação de acessibilidade na aquisição de TA, adaptação de seus edifícios para acesso universal do setor público e capacitação de docentes e de servidores, visando proporcionar ao usuário um atendimento eficiente e adequado.

\section{Estudo de caso na UFTM}

A Universidade Federal do Triângulo Mineiro (UFTM) é uma autarquia pública vinculada ao Ministério da Educação, sendo uma IFES com a finalidade de ensino, pesquisa e extensão. A instituição foi fundada em 27 de abril de 1953, primeiramente, com a denominação de Faculdade de Medicina do Triângulo Mineiro. Em 2005, houve a transformação em Universidade, mediante a denominação de Universidade Federal do Triângulo Mineiro (UFTM), pela Lei 11.152, de 29 de julho de 2005 (BRASIL, 2005). Trata-se de universidade de reconhecimento nacional, possuindo campi nas cidades Uberaba e Iturama, ambas do Triângulo Mineiro, além de um Complexo Cultural e Científico situado na cidade de Peirópolis. Na cidade de Uberaba, a Universidade possui cinco institutos científicos, sendo eles: Instituto de 
Ciências da Saúde - ICS, Instituto de Ciências Exatas, Naturais e Educação ICENE, Instituto de Ciências Tecnológicas e Exatas - ICTE, Instituto de Educação, Letras, Artes, Ciências Humanas e Sociais - IELACHS e o Instituto de Ciências Biológicas e Naturais - ICBN (PORTAL UFTM, 2019).

Observa-se que a instituição possui um número expressivo de 7550 alunos de graduação, pós-graduação e cursos profissionalizantes, advindos de diversas localidades do país, 621 docentes e 3711 técnicos-administrativos. Dessa forma, observa-se que o funcionamento da instituição envolve uma grande quantidade de pessoas da comunidade acadêmica que possuem uma diversidade de características (PORTAL UFTM, 2019). Vale destacar que, na instituição, há pessoas com algum tipo de deficiência ou com mobilidade reduzida. Constata-se que há vários servidores e alunos, na instituição, com deficiências tanto de nascença, como adquiridas ao longo da vida. No entanto, observa-se que nem todos declaram sua deficiência ao ingressar na universidade.

De acordo com os dados disponibilizados pela Pró-Reitoria de Recursos de Humanos da UFTM (Tabela 1), referentes ao ano de 2019, constatou-se que existem 25 servidores na instituição com deficiência.

Tabela 1 - Servidores com deficiência na UFTM.

\begin{tabular}{c|c|c|c|c}
\hline $\begin{array}{c}\text { CONTAGEM DE } \\
\text { SERVIDOR }\end{array}$ & \multicolumn{4}{|c}{ CARREIRA } \\
\hline UPAG & COD_SIAPECAD & PROF 3 & TÉCNICO & Total Geral \\
\hline UFTM & A10-AUDITIVA & 2 & 5 & 6 \\
& A22-BAIXA VISÂO & 1 & 2 & 3 \\
& A30-FÍSICA & 2 & 13 & 15 \\
\hline & A21-CEGUEIRA & & 1 & 1 \\
\hline & UFTM Total & $\mathbf{5}$ & $\mathbf{2 1}$ & $\mathbf{2 5}$ \\
\hline
\end{tabular}

Fonte: Dados Pró- Reitoria de Recursos Humanos - UFTM, 2019.

Segundo dados disponibilizados pelo Departamento de Registro e Cadastro de Alunos, DRCA - UFTM referentes ao ano de 2019, constata-se que existem 60 discentes na instituição com deficiência, totalizando 85 pessoas com deficiência na universidade. Dentre os servidores declarantes na 
instituição, observa-se deficiência auditiva, visual e física, como mostra a Tabela 1. Em relação aos discentes, o número é mais expressivo, totalizam sessenta alunos com algum tipo de deficiência. Conforme pode ser observado na Tabela 2, esses alunos possuem deficiências visuais, auditiva, física, além de outras síndromes (não especificadas pelos alunos) e estão matriculados em diversos cursos de graduação na instituição.

Tabela 2 - Alunos com deficiência por curso de graduação na instituição

\begin{tabular}{|c|c|c|}
\hline CÓDIGO DO CURSO & TIPO DE DEFICIÊNCIA & QUANTIDADE \\
\hline \multirow{5}{*}{101 - MEDICINA } & Altas Habilidades & 1 \\
\hline & Autismo & 2 \\
\hline & Baixa Visão & 1 \\
\hline & Física & 5 \\
\hline & Outras Necessidades & 1 \\
\hline 103 - BIOMEDICINA & Baixa Visão & 1 \\
\hline $104-$ FISIOTERAPIA & Baixa Visão & 1 \\
\hline \multirow{3}{*}{106 - TERAPIA OCUPACIONAL } & Auditiva & 1 \\
\hline & Baixa Visão & 1 \\
\hline & Outras Necessidades & 2 \\
\hline \multirow{2}{*}{107 - PSICOLOGIA } & Baixa Visão & 2 \\
\hline & Outras Necessidades & 1 \\
\hline \multirow{2}{*}{108 - EDICAÇÃO FÍSICA } & Física & 1 \\
\hline & Outras Necessidades & 1 \\
\hline 109 - CIENCIAS BIOLÓGICAS & Baixa Visão & 1 \\
\hline 201 - LETRAS INGLES & Baixa Visão & 2 \\
\hline 202 - LETRAS ESPANHOL & Cegueira & 2 \\
\hline $203-$ GEOGRAFIA & Baixa Visão & 1 \\
\hline \multirow{4}{*}{204 - HISTÓRIA } & Baixa Visão & 2 \\
\hline & Cegueira & 1 \\
\hline & Outras Necessidades & 1 \\
\hline & Síndrome de Asperger & 1 \\
\hline \multirow{5}{*}{205 - SERVIÇO SOCIAL } & Altas Habilidades & 1 \\
\hline & Auditiva & 1 \\
\hline & Baixa Visão & 3 \\
\hline & Física & 3 \\
\hline & Outras Necessidades & 1 \\
\hline \multirow{2}{*}{$301-$ FISICA } & Baixa Visão & 1 \\
\hline & Física & 1 \\
\hline 313 - ENGENHARIA DE ALIMENTOS & Baixa Visão & 1 \\
\hline 314 - ENGENHARIA DE PRODUÇAO & Baixa Visão & 1 \\
\hline \multirow{2}{*}{315 - ENGENHARIA ELETRICA } & Baixa Visão & 1 \\
\hline & Surdo cegueira & 1 \\
\hline \multirow[t]{2}{*}{316 - ENGENHARIA MECANICA } & Auditiva & 1 \\
\hline & Cegueira & 1 \\
\hline
\end{tabular}




\begin{tabular}{c|c|c}
\hline $317-$ ENGENHARIA QUÍMICA & Baixa Visão & 2 \\
\hline 403 - QUIMICA - ITURAMA & Outras Necessidades & 1 \\
\hline $406-$ AGRONOMIA - ITURAMA & Baixa Visão & 1 \\
\hline $409-$ CIÉNCIAS BIOLÓGICAS - & Outras Necessidades & 2 \\
ITURAMA & Baixa Visão & 1 \\
\hline $2501-$ LE CAMPO & Outras Necessidades & 1 \\
\hline Totas Habilidades & 1 \\
\hline 2503-LE CAMPO - MATEMATICA & Baixa Visão & 1 \\
\hline Total Resultado & Física & 1 \\
\hline
\end{tabular}

Fonte: Divisão de Registro e Controle Acadêmico - UFTM, 2019.

A Avaliação do total de pessoas com deficiência, na UFTM, mostra que há uma demanda na comunidade acadêmica pela total adoção das políticas públicas de acessibilidade na instituição, visando proporcionar um serviço que atenda também as minorias. Para isso, a instituição deve estar em consonância ao disposto no Estatuto da Pessoa com Deficiência (BRASIL, 2015), em seu inciso XVI do artigo 28, o qual garante o direito à acessibilidade a toda a comunidade acadêmica, referente às edificações, aos ambientes e às atividades relacionadas a todas as modalidades, etapas e níveis de ensino.

Dessa forma, salienta-se que a Universidade como sendo fonte de conhecimento e valores, deve ser exemplo em proporcionar o ensino a todos, independentemente de suas particularidades, principalmente, porque 0 indivíduo com uma deficiência particular pode possuir outras potencialidades que precisam ser aproveitadas e valorizadas no campo do conhecimento, 0 que exige profissionais capacitados e preparados para o recebimento de diversos alunos.

Com o intuito de verificar os planejamentos em Acessibilidade na instituição, foram colhidas informações a partir dos relatórios da Comissão Permanente e Avaliação CPA-UFTM, disponíveis no sítio da instituição (http://uftm.edu.br/comitesecomissoes/CPA/relatorios). Inicialmente, constatouse que a universidade acrescentou a inclusão social como um dos valores defendidos pela universidade, como previsto em seu estatuto social (UFTM, 2016), no inciso II do art. ํ 7. Na instituição, desde 2011, foi efetivado o Núcleo de Acessibilidade vinculado a Pró-Reitoria de Assuntos Acadêmicos e 
Estudantis (PROACE-UFTM). Esse núcleo é composto por três profissionais intérpretes em Libras, duas servidoras e uma técnica em assuntos educacionais especialista em deficiência visual. O objetivo do núcleo consiste na garantia de recursos acessíveis para alunos com deficiência, buscando a permanência e conclusão do curso por parte desses alunos.

Foi relatado em resposta ao questionamento via e-SIC sobre as TA disponíveis à comunidade acadêmica com deficiência da UFTM e esses dados podem ser observados na Quadro 2. Segundo informações da UFTM, atualmente, a universidade dispõe de computadores com leitores de tela, lupas ópticas e eletrônicas, leitores autônomos, máquina fusora de relevos, bengala de rastreamento, máquina de escrever, Braille, impressora Braille, cadeiras de rodas e cadeiras específicas.

Quadro 2: Dados institucionais sobre Tecnologia disponível aos alunos com deficiência na UFTM.

\begin{tabular}{|c|c|}
\hline $\begin{array}{l}\text { Quantidade de } \\
\text { servidores no setor } \\
\text { responsável na } \\
\text { instituição }\end{array}$ & $\begin{array}{l}\text { - } 3 \text { servidores intérpretes em Libras; } \\
\text { - } \quad 2 \text { servidores técnico administrativos; } \\
\text { - } \quad 1 \text { técnico em assuntos educacionais } \\
\text { especialista em deficiência visual; }\end{array}$ \\
\hline $\begin{array}{l}\text { Tecnologia Assistiva } \\
\text { disponíveis na } \\
\text { instituição }\end{array}$ & $\begin{array}{l}\text { - } \quad \text { computadores com leitores de tela; } \\
\text { - } \quad \text { lupas ópticas e eletrônicas; } \\
\text { - } \quad \text { leitores autônomos; } \\
\text { - } \quad \text { máquina fusora de relevos; } \\
\text { - } \quad \text { bengala de rastreamento; } \\
\text { - } \quad \text { máquina de escrever Braille; } \\
\text { - } \quad \text { impressora Braille; } \\
\text { - } \quad \text { cadeiras de rodas; } \\
\text { - } \quad \text { cadeiras específicas; } \\
\text { - } \quad \text { seis computadores adaptados com software e } \\
\text { interface acessível }\end{array}$ \\
\hline $\begin{array}{c}\text { Tecnologia Assistiva } \\
\text { ainda não disponíveis } \\
\text { na instituição, mas } \\
\text { necessárias segundo } \\
\text { a instituição }\end{array}$ & $\begin{array}{l}\text { - equipamentos para áudio, descrição/ tradução } \\
\text { simultânea; }\end{array}$ \\
\hline $\begin{array}{l}\text { Espaços adaptados } \\
\text { na instituição }\end{array}$ & $\begin{array}{l}\text { - sala especializada para uso de alunos com } \\
\text { deficiência; } \\
\text { - } \quad \text { piso tátil; } \\
\text { - } \quad \text { placas em Braille; }\end{array}$ \\
\hline
\end{tabular}




\begin{tabular}{|l|ll|}
\hline $\begin{array}{l}\text { Curso de capacitação } \\
\text { na instituição na área }\end{array}$ & $\bullet$ & Libras \\
\hline $\begin{array}{l}\text { Projetos de pesquisa } \\
\text { na instituição na área }\end{array}$ & $\bullet$ & nenhum \\
\hline
\end{tabular}

Fonte: Dos autores, 2021.

Possui ainda uma sala especializada para uso de alunos com deficiência, seis computadores adaptados com software e interface acessível. Além disso, o setor proporciona o empréstimo de materiais ampliados. Dentre as tecnologias ofertadas a toda comunidade foi citado piso tátil, rampas, elevadores, placas em Braille, barras de acesso/apoio e softwares gratuitos (lupas e leitores de tela). Quanto aos equipamentos de TA que a Universidade precisa adquirir foi destacado a necessidade de equipamentos para áudio, descrição/tradução simultânea.

A UFTM informou ainda que a equipe do Departamento de Assistência Estudantil, por meio do Setor de Acessibilidade e Acompanhamento Pedagógico, executa a adaptação de material pedagógico e textos para alunos com deficiência visual, realiza a tradução e interpretação de Libras/Português; elabora projetos de sensibilização quanto ao tema "inclusão" e "diversidade"; acompanha as demandas de acessibilidade em toda a comunidade da UFTM; proporciona as TA para mediar a informação. Além disso, o setor disponibiliza os Programas de Tutoria Inclusiva e Monitoria Inclusiva.

A instituição salientou ainda que o setor desenvolve projetos visando promover a acessibilidade e inclusão na UFTM, tais como: Programa de Promoção e Efetivação da Acessibilidade e Inclusão - PROPEACI; Projeto Outros Olhos buscando melhorar a interação das pessoas com deficiência visual nos espaços da instituição; Projeto Azul da UFTM, evento voltado para homenagear a comunidade surda de Uberaba - MG; Rodas de Conversa: Como o Mundo vê a Inclusão e Como Podemos vê-la, que consiste em debate de temas vinculados à acessibilidade; Cursos de Português como L2 para surdos.

Questionada sobre a existência de capacitação na instituição para preparação de alunos, técnicos administrativos e docentes visando o melhor 
atendimento de pessoas com deficiência, verificou-se que a UFTM oferta a disciplina Libras para os cursos de Licenciatura, Serviço Social e nos sete cursos de Engenharias que oferta. Quanto à capacitação de servidores, também se verificou que houve oferta de capacitação em 2018, e que em 2020 foi incluída na programação a abertura de uma nova turma do curso de Libras.

Além disso, quanto ao desenvolvimento da Inovação Tecnológica na instituição para melhorias na área de acessibilidade, Tecnologia Assistiva e Inclusão social e sobre a existência de projetos pesquisa sobre a temática do presente estudo, a UFTM informou que após consulta em seu sistema de projetos cadastrados na Pró-Reitoria de Pesquisa e Pós-Graduação, não se encontraram projetos vigentes que constem em seu título e/ou resumo os termos "acessibilidade" e "tecnologia assistiva". Entretanto, é de conhecimento que existe uma docente no Departamento de Terapia Ocupacional, a docente Alessandra Cavalcanti de Albuquerque e Souza, que desenvolve pesquisa sobre Tecnologia Assistiva, tem artigos publicados em revistas científicas da área e inclusive tem um depósito de patente na área. Dessa forma, verifica-se a necessidade de ampliar o incentivo para produção científica nesta área na instituição, especialmente considerando os benefícios que a Inovação Tecnológica, com a criação de produtos e serviços acessíveis, pode trazer para a sociedade brasileira.

Visando obter-se informações sobre as adaptações físicas feitas na instituição para atender as normas de acessibilidade, foi feito questionamento à UFTM pelo portal e-Sic. O questionamento feito referiu-se às medidas tomadas para atender a acessibilidade, na instituição. O questionamento obteve como resposta que as barreiras arquitetônicas existentes nas edificações antigas da instituição, como as da Unidade Manoel Terra, Reitoria e Biblioteca Frei Eugênio, foram eliminadas com o aumento das dimensões de portas, retirada dos desníveis com altura superior a $5 \mathrm{~mm}$ e criação de rampas de acesso e instalação de plataformas de transposição de nível nos locais em que não foi possível a construção de rampas. Também foi informado que foram feitas reformas e construídos diversos sanitários adaptados para o uso por pessoas com deficiência. Além disso, foi informado que todas as novas edificações 
foram projetadas em consonância com a norma de acessibilidade NBR9050, sem barreiras arquitetônicas (ABNT, 2015). Quanto à carência informada pela instituição, essa informou a falta de implantação da parte de sinalização com o piso tátil direcional e identificação dos ambientes em Braille e a justificativa refere-se à falta de recursos financeiros para essas implementações.

A UFTM também informou que as Bibliotecas Central e Setorial da Univerdecidade possuem: banheiros e bebedouros adaptados; entrada e saída com dimensionamento; a Biblioteca Central possui cápsula de transposição de nível; o mobiliário é adaptado; os ambientes são desobstruídos para facilitar a movimentação de cadeirantes e pessoas com deficiência visual; o sítio da UFTM/Biblioteca é desenvolvido para que pessoas percebam, compreendam, naveguem e utilizem os serviços oferecidos; a Biblioteca Central possui uma cabine Multimídia com equipamentos de acessibilidade que são operacionalizados pelo Núcleo de Acessibilidade da PROACE: Leitor autônomo, computador com leitor de tela, máquina de escrever Braille Perkins e lupa eletrônica.

Para avaliar se o crescimento físico da instituição realmente tem se dado respeitando-se a legislação vigente (ABNT, 2015), foi feita pesquisa de campo aos diversos prédios do campus Uberaba e Iturama da UFTM. A partir dos resultados obtidos nessas visitas, conforme o Quadro 3, verifica-se que foram realizadas reformas e adaptações em algumas edificações, visando adequação às normas vigentes, respeitando-se os princípios de acessibilidade, mas não em todas. A instituição desenvolveu ações de acessibilidade, seguindo o Programa Incluir: Acessibilidade na Educação Superior do Ministério da Educação para a implementação da sinalização horizontal (piso tátil), visual e em Braille.

Nessa pesquisa, foram considerados como importantes para garantir acessibilidade em instituição públicas os seguintes itens: a existência de rampas ou elevadores para acesso aos setores, estacionamentos com vagas preferenciais para pessoas com deficiência, idosos, bebedouros acessíveis, sanitários universais ou adaptados, portas com largura acessível, acessibilidade dos espaços e móveis usados pelos servidores, balcão de 
atendimento com altura adequada, a existência de piso tátil e sinalização em Braille nos diversos setores da instituição, como manda a NBR 9050 (ABNT, 2015).

Quadro 3: UFTM - Medidas de acessibilidade: disponibilidade e ausência.

\begin{tabular}{|c|c|c|}
\hline \multicolumn{3}{|c|}{ UFTM } \\
\hline PRÉDIO & MEDIDAS DE ACESSIBILIDADE & AUSÉNCIA \\
\hline ICTE unidade I & $\begin{array}{l}\text { - Rampas; } \\
\text { - Estacionamento com vagas para } \\
\text { pessoas com deficiência; } \\
\text { - Bebedouros acessíveis; } \\
\text { - Sanitário para pessoas com deficiência } \\
\text { - Balcão de atendimento com altura } \\
\text { acessível; }\end{array}$ & $\begin{array}{l}\text { - } \quad \text { Piso tátil; } \\
\text { - } \quad \text { sinalização em Braile; }\end{array}$ \\
\hline ICTE unidade II & $\begin{array}{l}\text { - Rampas; } \\
\text { - Piso tátil para entrada principal parte } \\
\text { administrativa } \\
\text { - Estacionamento com vagas para } \\
\text { pessoas com deficiência } \\
\text { - Bebedouros acessíveis; } \\
\text { - Sanitário para pessoas com } \\
\text { deficiência; } \\
\text { - Balcão de atendimento com altura } \\
\text { acessível; }\end{array}$ & $\begin{array}{l}\text { - Cobertura para rampas externas (em } \\
\text { períodos de chuvas dificultará ao } \\
\text { acesso de pessoa deficiente ou com } \\
\text { mobilidade reduzida); } \\
\text { - Piso tátil; } \\
\text { - } \quad \text { sinalização em Braile; }\end{array}$ \\
\hline ICENE & $\begin{array}{l}\text { - } \text { Rampas; } \\
\text { - Estacionamento com vagas para } \\
\text { pessoas com deficiência; } \\
\text { - Bebedouros acessíveis; } \\
\text { - Sanitário para pessoas com } \\
\text { deficiência; } \\
\text { - Atendimento nas salas de forma } \\
\text { acessível; }\end{array}$ & $\begin{array}{l}\text { - } \quad \text { Piso tátil; } \\
\text { - } \quad \text { sinalização em Braile; }\end{array}$ \\
\hline $\begin{array}{c}\text { Biblioteca } \\
\text { Univerdecidade }\end{array}$ & $\begin{array}{l}\text { - Rampas; } \\
\text { - Estacionamento com vagas para } \\
\text { pessoas com deficiência; } \\
\text { - } \text { Bebedouros acessíveis; } \\
\text { - Sanitário para pessoas com } \\
\text { deficiência; }\end{array}$ & $\begin{array}{l}\text { - } \quad \text { Piso tátil; } \\
\text { - } \quad \text { Sinalização em Braille; } \\
\text { - } \quad \text { Balcão altura acessível; }\end{array}$ \\
\hline $\begin{array}{l}\text { Biblioteca } \\
\text { Central }\end{array}$ & $\begin{array}{l}\text { - Rampas; } \\
\text { - Elevador; } \\
\text { - } \text { Bebedouros acessíveis; } \\
\text { - Sanitário para pessoas } \\
\text { - } \text { deficiência; } \\
\text { Balcão com altura acessível; }\end{array}$ & $\begin{array}{l}\text { - } \quad \text { Piso tátil; } \\
\text { - } \quad \text { sinalização em Braile; }\end{array}$ \\
\hline Reitoria & $\begin{array}{l}\text { - Rampas; } \\
\text { - Elevadores; } \\
\text { - } \text { Bebedouros acessíveis; } \\
\text { - Sanitário para pessoas }\end{array}$ & $\begin{array}{l}\text { - Cobertura para rampa externa } \\
\text { entrada (em períodos de chuvas } \\
\text { dificultará ao acesso de pessoa } \\
\text { deficiente ou com mobilidade }\end{array}$ \\
\hline
\end{tabular}




\begin{tabular}{|c|c|c|}
\hline & $\begin{array}{l}\text { deficiência; } \\
\text { - Atendimento em salas de forma } \\
\text { acessível; }\end{array}$ & $\begin{array}{l}\text { reduzida); } \\
\text { - } \quad \text { Piso tátil; } \\
\text { - Sinalização em Braile; } \\
\text { ausência de rampas nos } 2^{\circ} \text { e } 3^{\circ} \\
\text { andar (em caso de elevador com } \\
\text { problema dificultará o acesso de } \\
\text { pessoa com deficiência); }\end{array}$ \\
\hline $\begin{array}{c}\text { Centro } \\
\text { Educacional }\end{array}$ & $\begin{array}{ll}\text { - } & \text { Piso tátil; } \\
\text { - } & \text { Sinalização em Braille; } \\
\text { - } & \text { Elevadores; } \\
\text { - } & \text { Estacionamento com vagas para } \\
& \text { pessoas com deficiência; } \\
\text { - } & \text { Bebedouros acessíveis; } \\
\text { - } & \text { Sanitário para pessoas com deficiência }\end{array}$ & $\begin{array}{l}\text { - Cobertura para rampas externas (em } \\
\text { períodos de chuvas dificultará ao } \\
\text { acesso de pessoa deficiente ou com } \\
\text { mobilidade reduzida); }\end{array}$ \\
\hline $\begin{array}{l}\text { CEA- Centro } \\
\text { Educacional e } \\
\text { Administrativo }\end{array}$ & $\begin{array}{l}\text { - Rampas; } \\
\text { - Elevadores; } \\
\text { - } \quad \text { Estacionamento com vagas para } \\
\text { pessoas com deficiência; } \\
\text { - } \text { Bebedouros acessíveis; } \\
\text { - Sanitário para pessoas com deficiência } \\
\text { - } \quad \text { Cursos com atendimento em salas de } \\
\quad \text { forma acessível; }\end{array}$ & $\begin{array}{l}\text { - Cobertura para rampas externas (em } \\
\text { períodos de chuvas dificultará ao } \\
\text { acesso de pessoa deficiente ou com } \\
\text { mobilidade reduzida); } \\
\text { - } \quad \text { Piso tátil; } \\
\text { - Sinalização em Braile; } \\
\text { - DRCA (balcão de atendimento com } \\
\text { altura adaptada); }\end{array}$ \\
\hline NASS & $\begin{array}{l}\text { - Rampas; } \\
\text { - } \text { Bebedouros acessíveis; } \\
\text { - Sanitário acessível; } \\
\text { atendimento em salas de forma } \\
\text { acessível; }\end{array}$ & - $\quad$ Piso tátil; \\
\hline PRORH & $\begin{array}{l}\text { - Bebedouro acessível; } \\
\text { - Sanitário universal; } \\
\text { - Atendimento em salas de forma } \\
\text { acessível; }\end{array}$ & $\begin{array}{l}\text { - } \quad \text { Piso tátil; } \\
\text { - Sinalização em Braile; } \\
\text { - } \quad \text { Esmpas ou elevadores; } \\
\text { pessoanamento com vaga para } \\
\text { - Sanitário acessível no segundo piso } \\
\text { e próximo ao estacionamento - } \\
\text { térreo; }\end{array}$ \\
\hline DTI & $\begin{array}{l}\text { - } \quad \text { Bebedouro acessível; } \\
\text { - } \quad \text { Sanitário acessível; } \\
\text { Piso tátil para entrada principal parte } \\
\text { administrativa }\end{array}$ & $\begin{array}{l}\text { - } \quad \text { Piso tátil; } \\
\text { - Sinalização em Braile; } \\
\text { - } \quad \text { Estacionamento com vaga para } \\
\text { - Ressoas com deficiência; } \\
\text { - Rampa ou elevador para 20 piso }\end{array}$ \\
\hline $\begin{array}{l}\text { UNIDADE } \\
\text { PRAÇA } \\
\text { MANOEL } \\
\text { TERRA }\end{array}$ & $\begin{array}{l}\text { - } \text { Bebedouro acessível; } \\
\text { - Elevador com acesso aos primeiros e } \\
\text { segundo andar na maioria dos prédios } \\
\text { - Sanitário acessível; } \\
\text { - Atendimento em salas de forma } \\
\text { acessível; } \\
\text { - Estacionamento com vagas para } \\
\text { pessoas com deficiência; }\end{array}$ & $\begin{array}{l}\text { - } \quad \text { Piso tátil; } \\
\text { - } \quad \text { Sinalização em Braile; } \\
\text { setor de patologia; } \\
\text { - Elevador que funcione para } 3^{\circ} \text { andar } \\
\quad \text { ou rampas; }\end{array}$ \\
\hline PATRIMÔNIO & $\begin{array}{l}\text { - Rampas } \\
\text { - Bebedouro acessível } \\
\text { - Atendimento em salas de forma }\end{array}$ & $\begin{array}{l}\text { - Piso tátil } \\
\text { - } \quad \text { Placas de identificação dos setores } \\
\text { - Sinalização em braile }\end{array}$ \\
\hline
\end{tabular}




\begin{tabular}{|c|c|c|}
\hline & acessível & $\begin{array}{l}\text { - } \quad \text { Sanitário acessível } \\
\text { - } \quad \text { Elevador ou rampas para acesso ao } \\
2^{\circ} \text { andar (parte administrativa) } \\
\text { - Estacionamento com vagas } \\
\text { preferenciais }\end{array}$ \\
\hline ITURAMA & $\begin{array}{l}\text { - Rampas } \\
\text { - Atendimento em salas de forma } \\
\text { - } \text { Messível } \\
\text { - Sanitários acessíveis } \\
\text { - } \quad \text { Piso tátil para entrada principal parte } \\
\text { administrativa }\end{array}$ & $\begin{array}{ll}\text { - } & \text { Piso tátil } \\
\text { - Sinalização em braile } \\
\text { - } \\
\text { Estacionamento com } \\
\text { preferenciais }\end{array}$ \\
\hline
\end{tabular}

Fonte: Dos autores, 2021.

Observa-se que itens como rampas, bebedouros acessíveis, sanitários universais, balcão de atendimento em altura adequada ou salas acessíveis para atendimento foram itens atendidos na maioria dos setores da universidade, garantindo acessibilidade em consonância com o Estatuto da Pessoa com Deficiência (BRASIL, 2015) e com a NBR 9050 (ABNT, 2015). Observa-se ainda a adoção de rampas para acesso, identificadas em diversos setores da UFTM. No entanto, observa-se que as rampas não são cobertas o que causa transtorno para uma pessoa com mobilidade reduzida em dias chuvosos. Assim como as escadas são cobertas, é importante que os prédios públicos também realizem essa adaptação para proporcionar qualidade e comodidade no acesso para todos.

Ressalta-se que o item sinalização em Braille somente foi identificado no Prédio do Centro Educacional, em que se verificou placas em Braille para indicação de salas e laboratórios. Também se constatou que algumas placas em Braille foram danificadas e arrancadas neste setor da instituição, o que demonstra claramente a existência de barreira atitudinal, que consiste em comportamento que impede e prejudica "a participação social da pessoa com deficiência em igualdade de condições e oportunidades com as demais pessoas", conforme Lei 10098/2000 (BRASIL, 2000).

Além disso, durante a realização da pesquisa em campo, houve impedimento de fotografar alguns setores da instituição, por considerarem que demonstraria uma imagem negativa do setor, mostrando a falta de acessibilidade. No entanto, a ocultação do problema, impede implementar a 
acessibilidade no setor, sendo assim, uma barreira atitudinal que prejudica suprir as necessidades para garantir o pleno exercício do direito do público com deficiência na instituição. Conforme Xavier (2016) constatou em sua pesquisa, os obstáculos que têm limitado a efetiva inclusão social da pessoa com deficiência têm sido, principalmente, as barreiras atitudinais ocasionadas pela sociedade. Dessa forma, para que assim sejam eliminadas essas barreiras atitudinais, torna-se necessário ainda a conscientização da comunidade acadêmica com relação à importância da acessibilidade e inclusão social na universidade.

Ainda no Centro Educacional também se identificou a implementação completa do piso tátil para orientar pessoas com deficiência visual com a indicação de obstáculos como escadas e degraus; para orientar acesso a salas de aula e laboratórios, sanitários e elevadores. Enquanto, em outros setores que é presente o piso tátil, foram identificados somente para acesso à entrada principal do local, tais como no Instituto de Ciências Tecnológicas e Exatas (ICTE) e Departamento Tecnologia da Informação (DTI). Salienta-se a necessidade de investimento na implementação de piso tátil em toda a universidade, assim como foi realizado no prédio do Centro Educacional para melhor orientação de acesso para pessoas com deficiência visual.

Além disso, com a pesquisa de campo, verificou-se que os locais com maiores obstáculos à acessibilidade encontram-se em edificações mais antigas. Averiguou-se que há locais que somente podem ser acessados por meio de escadas, o que ocasiona barreira física a pessoas com deficiência física ou mobilidade reduzida. Pode-ser citar os imóveis onde funcionam a PróReitoria de Recursos Humanos (PRORH), Patrimônio e Departamento de Tecnologia da Informação (DTI), nos quais o segundo andar, que se encontra a parte administrativa, somente pode ser acessado via escada. Também se ressalta que na unidade Manoel Terra, o prédio em que se encontra a disciplina Patologia somente é acessado via escada.

Com relação à unidade da praça Manoel Terra ainda, trata-se de um prédio tombado, devido ao valor patrimonial cultural histórico e artístico para a cidade de Uberaba, Minas Gerais. Conforme Pereira (2006): 
Para promoção da acessibilidade aos bens históricos e culturais devem ser consideradas a diversidade de bens imóveis e as peculiaridades regionais, evitando a descaracterização dos ambientes construídos, por meio de estudos específicos para cada caso. Deste modo, as duas facetas do princípio da igualdade estariam sendo preservadas. Assim, será possível garantir a igualdade das pessoas portadoras de deficiência e das gerações futuras de apreciarem os bens imóveis de valor histórico e cultural.

Então, a administração pública deve realizar as adaptações necessárias para que o ambiente esteja em conformidade com as normas de acessibilidade do ordenamento jurídico brasileiro

Foi realizada pesquisa para averiguar se a universidade está em consonância com as normas de acessibilidade em seu portal eletrônico e verificou-se que esse segue o e-MAG (Modelo de Acessibilidade em Governo Eletrônico, que tem o compromisso de nortear o desenvolvimento e a adaptação de conteúdos digitais do governo federal, garantindo o acesso a todos). Observou-se que sua página inicial, possui um link que possibilita o usuário alterar o contraste da página de modo a facilitar a visualização, no caso de usuários com baixa visão, bem como possui um link para o usuário acessar uma página em seu sítio sobre acessibilidade, que traz atalhos para auxiliar o usuário na utilização do portal. O conteúdo disposto no sítio da Universidade pode ser acessado na modalidade em Libras, bastando o usuário baixar a ferramenta computacional V Libras, para que a informação disposta no portal também seja acessível ao deficiente visual. O portal traz que o V Libras é "um conjunto de ferramentas computacionais de código aberto, que traduz conteúdos digitais (texto, áudio e vídeo) para Língua Brasileira de Sinais LIBRAS, tornando computadores, celulares e plataformas Web acessíveis para pessoas surdas."

\section{CONCLUSÃO}

A partir da presente pesquisa foi possível concluir que com a expansão da legislação de proteção da pessoa com deficiência, os conceitos de inclusão social e acessibilidade se propagaram. Diante disso, as IES têm buscado 
eliminar as barreiras existentes, tanto no campo físico, quanto digital, bem como no ensino e aprendizagem, investindo na adaptação de suas edificações, na aquisição de TA e implementação de cursos de capacitação para promoverem a acessibilidade em seus campi. Investimentos em acessibilidade e inclusão influenciarão na garantia não somente do ingresso de alunos com deficiência, mas na permanência e conclusão de curso desses alunos. Além disso, tais investimentos proporcionarão ainda mais reconhecimento de um serviço público adequado e de qualidade a ser prestado a toda a sociedade. Com relação à UFTM, observou-se que a instituição já implementou várias medidas de acessibilidade em consonância com a legislação vigente, tais como aquisição de TA, adaptações na estrutura física, digital e implementação de Núcleo de Acessibilidade atuante, tem investido em seminários e rodas de conversas sobre acessibilidade e essas podem ser peças fundamentais na luta contra a barreira atitudinal e a conscientização da comunidade acadêmica acerca da inclusão social. Também verificou que um obstáculo enfrentado pela UFTM trata-se da dificuldade em adaptar estruturas mais antigas e promover a acessibilidade, em locais tombados. Entretanto, as edificações antigas da administração pública devem ser adaptadas para estarem em conformidade com as normas pertinentes à acessibilidade previstas no ordenamento jurídico brasileiro e assim garantir o exercício dos direitos fundamentais da igualdade em usufruir do espaço público, bem como de livre acesso ao ambiente.

\section{REFERÊNCIAS}

ASSOCIAÇÃO BRASILEIRA DE NORMAS TÉCNICAS. NBR 9050: 2015:

Acessibilidade a edificações, mobiliário, espaços e equipamentos urbanos. Rio de Janeiro: ABNT, 2015. Disponível em:

$<$ https://www.mdh.gov.br/biblioteca/pessoa-com-deficiencia/acessibilidade-aedificacoes-mobiliario-espacos-e-equipamentos-urbanos/>. Acesso em: 17 jul. 2020.

BERNARDES, Sandra. Caderno Técnico no. 9 - Mobilidade e acessibilidade urbana em centros históricos. Brasília, IPHAN, 2014.120p. ISBN: 978-857334-253-6. Disponível em: 
<http://portal.iphan.gov.br/uploads/publicacao/CadTec9_CadernoAcessibilidade _m.pdf>. Acesso em: 17 jul. 2020.

BRASIL. Presidência da República. Lei nº 10.098 de 19 de dezembro de 2000. Estabelece normas gerais e critérios básicos para a promoção da acessibilidade das pessoas portadoras de deficiência ou com mobilidade reduzida, e dá outras providências. Diário Oficial da União, Brasília, dez. 2000. Disponível em: <http://www.planalto.gov.br/ccivil_03/leis/l10098.htm>. Acesso em: 17 jul. 2020.

BRASIL. Presidência da República. Lei no 11.152, de 29 de julho de 2005. Transforma a Faculdade de Medicina do Triângulo Mineiro - FMTM em Universidade Federal do Triângulo Mineiro - UFTM e dá outras providências. Diário Oficial da União, Brasília, jul. 2005. Disponível em: <http://www.planalto.gov.br/ccivil_03/_Ato2004-2006/2005/Lei/L11152.htm>. Acesso em: 17 jul. 2020.

BRASIL. Presidência da República. Lei no 13.146, de 6 de julho de 2015. Institui a Lei Brasileira de Inclusão da Pessoa com Deficiência (Estatuto da Pessoa com Deficiência). Diário Oficial da União, Brasília, jul. 2015. Disponível em: <http://www.planalto.gov.br/ccivil_03/_ato20152018/2015/lei/l13146.htm>. Acesso em: 17 jul. 2020.

BRASIL. Ministério da Cultura. Instituto do Patrimônio Histórico e Artístico Nacional. Caderno Técnico no 09 - Mobilidade e acessibilidade urbana em centros históricos. Disponível em:

$<$ http://portal.iphan.gov.br/uploads/publicacao/CadTec9_CadernoAcessibilidade _m.pdf>. Acesso em: 17 jul. 2020.

BRASIL. Presidência da República. Decreto № 5.296 de 2 de dezembro de 2004. Disponível em: <http://www.planalto.gov.br/ccivil_03/_ato20042006/2004/decreto/d5296.htm>. Acesso em: 17 jul. 2020.

FERREIRA, Paloma Bessa. Acessibilidade, inclusão e inovação em Instituições Públicas de Ensino Superior: um estudo comparativo para elaboração de um Guia de acessibilidade para a UFTM. 2020. 89 f. Dissertação (Programa de Mestrado Profissional em Inovação Tecnológica) - Universidade Federal do Triângulo Mineiro, Uberaba, MG, 2020.

IBGE - Instituto Brasileiro de Geografia e Estatística. Censo Demográfico 2010: características da população e dos domicílios: resultados do universo. Rio de Janeiro, 2011. Disponível em:

<https://biblioteca.ibge.gov.br/visualizacao/periodicos/93/cd_2010_caracteristic as_populacao_domicilios.pdf>. Acesso em: 17 jul. 2020.

INEP - Instituto Nacional de Estudos e Pesquisas Educacionais Anísio Teixeira. Censo Escolar 2017. Disponível em: <http://portal.inep.gov.br/artigo/- 
/asset_publisher/B4AQV9zFY7Bv/content/inep-mec-divulga-censo-escolar2017/21206>. Acesso em: 17 jul. 2020.

ION. The World University Rankings, 2020. Disponível em:

<https://www.timeshighereducation.com/world-university-rankings/2020/latinamerica-university-

rankings\#!/page/0/length/25/sort_by/rank/sort_order/asc/cols/undefined>. Acesso em: 17 jul. 2020.

KAMIO, Lizandra \& SASSI, Onofre Cleuber. Inclusão social no turismo. Revista Saber Acadêmico, N.9, p.127-128, 2010.

PEREIRA, Ana Carolina Araújo. Acessibilidade em imóveis tombados MPMG. 2006. Disponível em:

<https://aplicacao.mpmg.mp.br/xmlui/bitstream/handle/123456789/872/3.2.3\%2 0Acessibilidade\%20em\%20im\%C3\%B3veis\%20tombados.pdf?sequence=1 $>$. Acesso em: 27 ago. 2019.

PORTAL da Universidade Federal do Triângulo Mineiro. Disponível em: <http://www.uftm.edu.br/institucional/conheca-a-uftm>. Acesso em: 27 ago. 2019.

SILVA, M. Jorge; MALFITANO, Ana Paula Serrata. Pesquisas bibliográficas nos moldes "estado da arte": produção de conhecimento científico. Revista Latinoamericana de Metodología de la Investigación Social, n.14. p.40-50, 2017.

TIMES HIGHER EDUCTAION, 2020. Disponível em:

$<$ https://www.timeshighereducation.com/world-university-rankings/2020/worldranking\#!/page/0/length/25/sort_by/rank/sort_order/asc/cols/stats>. Acesso em: $22 f e v$

UNIVERSIDADE FEDERAL DO TRIANGULO MINEIRO - UFTM. Estatuto da Universidade Federal do Triângulo Mineiro. Uberaba: UFTM, 2016.

Disponível em: <http://www.uftm.edu.br/proplan/regulamentacao-enormatizacao/estatuto>. Acesso em: 27 ago. 2019.

XAVIER, Avanci Duda. Inclusão da Pessoa com Deficiência: a grande barreira são as atitudes. In: CONGRESSO INTERNACIONAL DE EDUCAÇÃO INCLUSIVA, 2., 2016, Campina Grande. Anais [...] Campina Grande: UFPE, 2016. Disponível em:

https://editorarealize.com.br/revistas/conedu/trabalhos/TRABALHO_EV056_MD 1_SA14_ID8588_11082016164518.pdf

Recebido em: 11/09/2020

Aprovado em: 22/09/2021 


\section{CADERNOS}

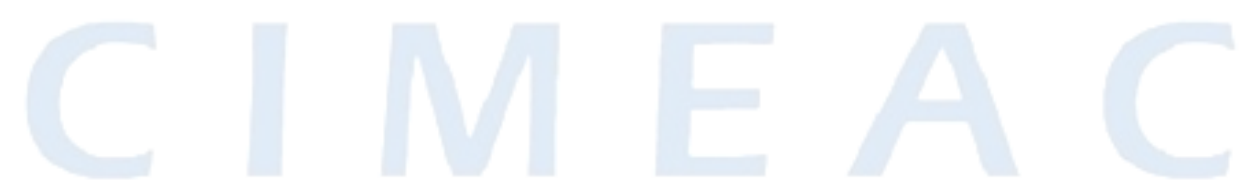

